\title{
Quality Improvement Initiative to Reduce Intravenous Line-related Infiltration and Phlebitis Incidence in Pediatric Emergency Room
}

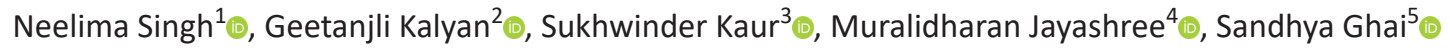

\begin{abstract}
Aim and objective: To reduce the incidence of infiltration and phlebitis by $50 \%$ over 2 months among children admitted to the emergency room (ER) of a tertiary care hospital.

Materials and methods: The study was conducted in the pediatric ER of a tertiary care hospital in North India. All children aged $>28$ days, receiving intravenous (IV) medication and/or fluids, were enrolled between June (2017) and September (2017). Existing practices of IV line insertion and maintenance were observed and recorded. The visual infusion phlebitis score and infiltration assessment scale used to grade the extent of the two. The intervention classified as "IV line insertion and maintenance bundle" included the introduction of low-cost mobile sterile compartment trays, audit and feedback, organizational change and introduction of infection control nurse. These interventions were implemented in sequential Plan-Do-Study-Act (PDSA) cycles. Reduction in the "incidence of phlebitis and infiltration" were the outcome measures while "scores on checklist of IV line insertion and IV line maintenance and administration of drugs" were the process measures.

Result: The process measures, for IV line insertion, maintenance and administration of drugs through IV line, revealed an increase in scores on the checklist. There was a significant decrease in the incidence of infiltration and phlebitis from $82.9 \%$ and $96.1 \%$ to $45 \%$ and $55 \%$, respectively, after implementation of all PDSA cycles.

Conclusion: Multifaceted QI IV line insertion and maintenance bundle reduced the incidence of infiltration and phlebitis. These interventions when integrated into daily work bundles along with continuous education and motivation helped in sustaining the goal and attaining longterm success.

Keywords: Infiltration, Pediatric emergency, Phlebitis, Quality improvement.

Indian Journal of Critical Care Medicine (2021): 10.5005/jp-journals-10071-23818
\end{abstract}

\section{INTRODUCTION}

Intravenous (IV) cannulation is a commonly performed procedure in sick children admitted to an emergency room (ER). Most common IV line-related complications include infiltration and phlebitis. ${ }^{1,2}$ Local swelling, redness, warmth, cording, and leakage of nonvesicant solution into the surrounding tissue leads to adverse outcomes. ${ }^{2}$ The incidence of phlebitis reported among patients receiving IV therapy is around $27-70 \%{ }^{3}$ A study conducted by White SA from Indiana revealed the highest (90\%) incidence of phlebitis. ${ }^{4}$ Another study conducted by Kaur et al. from India, at the outpatient department of an emergency, reported phlebitis to the tune of $56.5 \%$ and a significant association between phlebitis and duration of the cannula in situ. IV line-related infections are associated with the increased economic burden (ranging from US\$ 4888 to 11691), morbidity, duration of hospital stay (range 5-21 days), and mortality $(7-46 \%))^{6-8}$ Globally it has been found that each bloodstream infection (BSI) costs the hospital approximately $\$ 6000$ and increases the length of hospital stay by an additional week. ${ }^{9}$ In India, children with hospital-acquired BSIs spend 3.6 times more than those who do not acquire such infections. ${ }^{10}$

The causes of IV cannula induced phlebitis include cannulation by inexperienced staff, inappropriate disinfection of the site before insertion, multiple insertion attempts, administration of drugs and IV fluids with low pH (antibiotics like beta-lactams and vancomycin, potassium chloride, hypertonic glucose, lipids, and amino acids) and using high flow rates. ${ }^{11-13} \mathrm{~A}$ baseline survey to identify the incidence of phlebitis and infiltration conducted in our pediatric emergency unit revealed a high infiltration rate (82.9\%) and phlebitis (96.1\%). The barriers and facilitators related to IV line
'Department of Nursing, Vardhman Mahavir, Medical College and Safdarjung Hospital, New Delhi, India

2,3,5 National Institute of Nursing Education, PGIMER, Chandigarh, India ${ }^{4}$ Department of Pediatrics, PGIMER, Chandigarh, India

Corresponding Author: Geetanjli Kalyan, National Institute of Nursing Education, PGIMER, Chandigarh, India, Phone: +91 07696028309, e-mail: geetss2@gmail.com

How to cite this article: Singh N, Kalyan G, Kaur S, Jayashree M, Ghai S. Quality Improvement Initiative to Reduce Intravenous Line-related Infiltration and Phlebitis Incidence in Pediatric Emergency Room. Indian J Crit Care Med 2021;25(5):557-565.

Source of support: Nil

Conflict of interest: None

insertion and maintenance identified from a previous study were real eye-openers and were also used to shape the bundle. ${ }^{14}$

\section{Available Knowledge and Rationale}

Extensive literature review was done with more focus on MEDLINE, Scopus, Embase, and Cochrane databases before the intervention bundle was developed. ${ }^{14-21}$ The evidence revealed that many interventions help reduce infection/phlebitis, including hand hygiene. ${ }^{15-24}$ The use of the aseptic nontouch technique (ANTT) is one of the critical strategies to reduce infection in hospital setup. ${ }^{20,21,25}$ Other commonly used strategies to improve practices include quality improvement (QI) initiatives, audit/assessment and feedback to healthcare personnel (HCP), education of patient and 
HCPs, organizational changes, and reminder systems using a variety of methods. ${ }^{15-21,26-29}$ QI methods are the most effective way to identify and implement evidence-based interventions and improve care quality by employing Plan-Do-Study-Act (PDSA) cycles. ${ }^{28}$ In order to reduce higher rates of infiltration and phlebitis associated with IV lines, we conducted this QI study using a multifaceted "IV line insertion and maintenance bundle" adapted from the available literature and baseline data collected in our unit.

\section{Aim and Objective}

To reduce the incidence of infiltration and phlebitis by $50 \%$ over 2 months among children admitted to the ER of a tertiary care hospital.

\section{Materials and Methods}

The study was conducted in the standalone pediatric emergency unit of a tertiary care teaching and referral 300 bedded children's hospital with all diagnostic, curative, and rehabilitative facilities under one roof. The pediatric emergency unit is 22 bedded with annual visit and admission average of 25,000 and 12,000, respectively. During the study year (2016-2017), 11,695 children were admitted and treated in the emergency unit. Ethical clearance was taken from the (INT/IEC/2017/217 dated 17/03/17) Institute's Ethics Committee. Children aged $>28$ days, receiving IV medication and/or fluids admitted in ER, and their HCPs were enrolled in the study. Phlebitis, defined as the veins' intima's inflammation, was assessed by VIP score ${ }^{29}$ (visual infusion phlebitis score) and graded as $0,1,2,3,4,5$. Infiltration, defined as inadvertent leakage of a nonvesicant solution from its intended vascular pathway (vein) into the surrounding tissue during IV drug administration, was assessed using the infiltration assessment scale and graded $0,1,2,3,4 .^{26}$ All phlebitis and infiltration cases were identified and reported according to the different stages of the VIP score and infiltration assessment scale by the staff nurses. The study was conducted in three phases: preassessment, development of bundle, and implementation and adherence phase, and four different PDSA cycles. Although it is recommended to use sterile-additional packs to keep alcohol swabs and syringes, the observations made during the preassessment phase revealed that these sterile-additional packs' availability was limited. As there was no tray to keep the articles, the residents had to carry articles on their hands or in the pocket of lab coats; however, only a few could use sterile-additional packs and majority did not create any sterile field to carry the articles. Those who used sterile-additional packs kept both sterile and unsterile articles together except very few. The remaining others kept all the articles, such as a cannula, syringe, spirit swabs, and sampling vials, on the patient's bed before the procedure. During drug preparation and administration, by nurses although the trolley was cleaned with an alcohol swab before keeping the articles on the trolley, there was no demarcation for clean and sterile articles. When the medications were administered bed to bed, the articles, including pediatric drip sets, syringes, and drug vials, were kept directly on each bed's cardiac table. Every time the hand rub was not used before and during the procedure. Even after sampling, the vials and syringes were left on the patient's bed. The root cause of the lack of sterile IV line insertion and maintenance is depicted in Figure 1. The preassessment score on the IV line

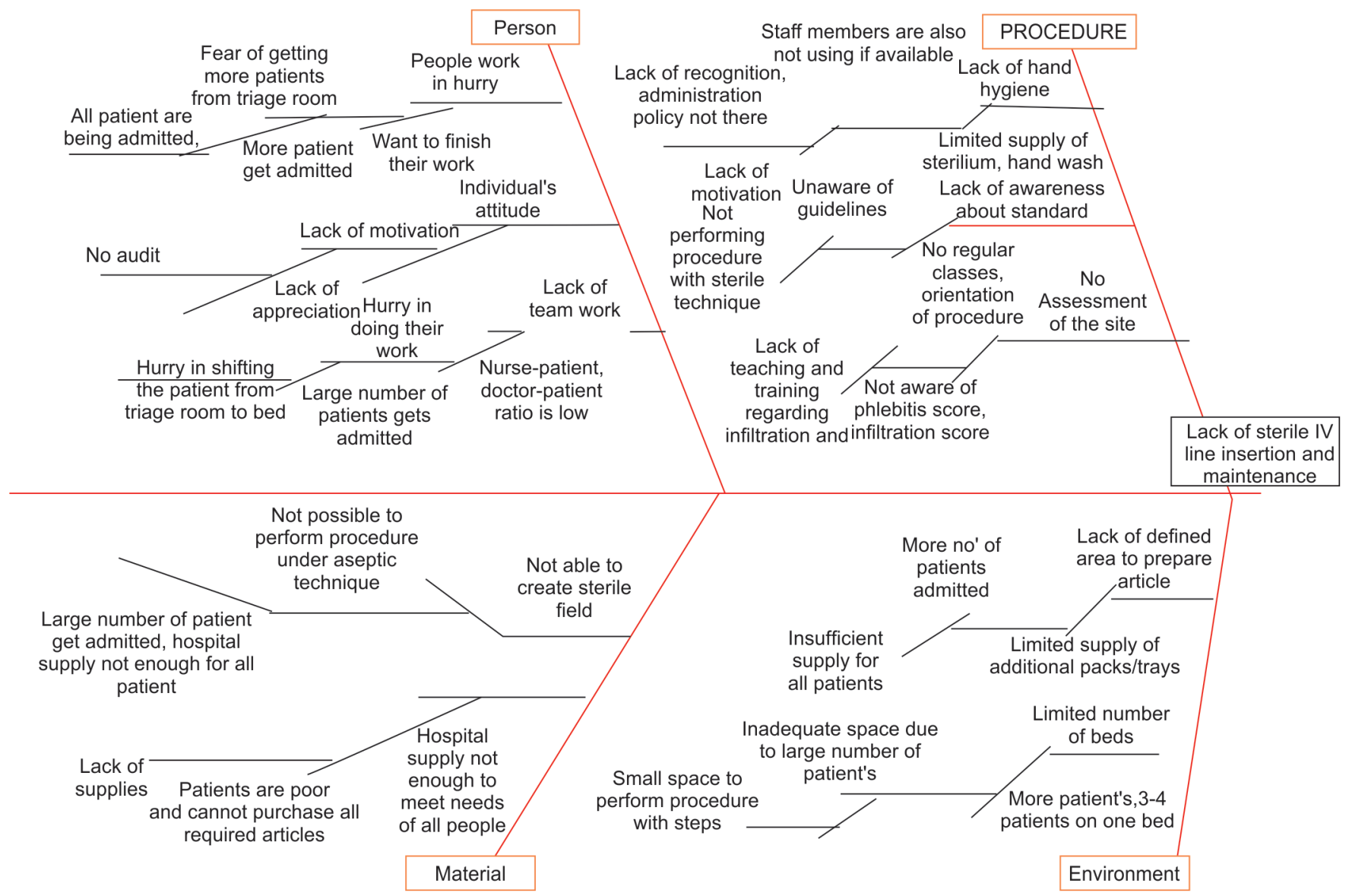

Fig. 1: Root cause analysis 
insertion checklist ranged between 8.69 and $43.47 \%$ and of drug administration ranged between 20.58 and $41.17 \%$. IV line insertion and maintenance bundles were developed for aseptic IV line insertion and its maintenance based on the best available evidence, problems identified, and suggested innovations and remedial measures. Reduction in the "incidence of phlebitis and infiltration" was outcome measures while "scores on checklist of IV line insertion and IV line maintenance and administration of drugs" were process measures. The opinion of HCPs was the balancing measure.

\section{Line Insertion and Maintenance Bundle}

Articles needed for aseptic insertion, including injection and cannulation trays, tourniquets, Tegaderm, hand rub, and gloves, were made available to the treating team. The bundle innovated using a low-cost stainless steel tray (Fig. 2), costing (INR 120-160) to prepare and arrange things needed to insert IV cannula and administer IV medications. This tray provided a compact and easy mobile sterile field after it was scrubbed with $70 \%$ alcohol or $2 \%$ chlorhexidine. ${ }^{21,26}$ After adequate hand hygiene with soap and water or alcohol gel, the tray was cleaned with alcohol wipes, first inside, then outside, and the bottom; this practice was based on ANTT practices. ${ }^{25}$ This low-cost innovation solved residents and nurses' problems by providing them a mobile sterile surface to segregate the sterile and unsterile articles in different trays compartments. The sterile articles were no longer kept on the beds or patients/trollies.

The evidence-based practices specific interventions were incorporated in the maintenance bundle included (i) use of lowcost trays, use of ANTT and appropriate material to secure the cannula ${ }^{25,30}$; (ii) site assessment using VIP score, ${ }^{29}$ and infiltration assessment scale, ${ }^{26}$ and documentation of the same in each shift ${ }^{31}$; (iii) removal of IV line if signs of phlebitis, infiltration, and blockage were present; (iv) IV line change only if clinically indicated rather than routinely after 72 hours. ${ }^{32}$ Other recommended interventions such as audit and feedback, organizational change, the introduction of infection control nurses, sending reminders, and QI team formulations were also used in sequential PDSAs. ${ }^{15-21,27}$ The details of the PDSA are given in Table 1.
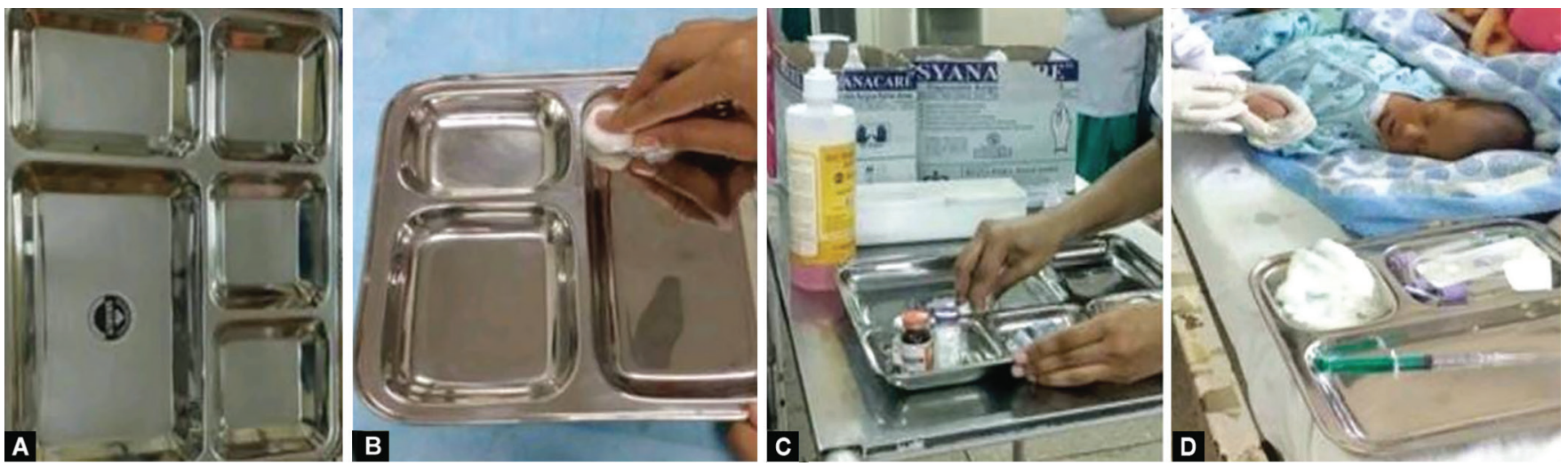

Figs 2A to D: (A and B) Drug administration and IV line insertion trays. ( $C$ and $D$ ) Use of $70 \%$ alcohol to clean the trays

Table 1: Details of PDSA

\begin{tabular}{|c|c|c|c|}
\hline PDSA-1 & PDSA-2 & PDSA-3 & PDSA-4 \\
\hline $\begin{array}{l}\text { A quality improvement team (QI team 1) (investigator, nurse } \\
\text { educator, administrator of unit, senior resident, and few } \\
\text { nurses to keep the record) was formed. } \\
\text { This team educated and sensitized } 2-3 \mathrm{HCP} \text { 's at a time } \\
\text { by presenting the preassessment findings (pictures of } \\
\text { prevalent practices, barriers, and facilitators related IV line } \\
\text { insertion and maintenance) } \\
\text { The feedback of existing challenges was given and aseptic IV } \\
\text { line insertion and maintenance were taught via powerpoint } \\
\text { presentations, videos, and demonstrations (skin prepara- } \\
\text { tion, fixing of the cannula, administration of medication, and } \\
\text { maintenance of IV line using trays) and repeat demonstra- } \\
\text { tions were taken. } \\
\text { The checklists for these procedures were displayed in } \\
\text { pediatric emergency at strategic places, pamphlets were } \\
\text { provided, posters were placed in the unit, and reminders } \\
\text { were circulated on focus groups created on social media } \\
\text { platform (whatsapp). } \\
\text { The use of infiltration and phlebitis assessment scales were } \\
\text { taught to HCP's and the same were displayed in the pediatric } \\
\text { emergency as well as in the duty rooms. The nursing person- } \\
\text { nel and investigator documented the scores in each shift. }\end{array}$ & $\begin{array}{l}\text { QI team } 2 \text { was formed at } \\
\text { the end of the first PDSA } \\
\text { and implemented in the } \\
\text { second PDSA cycle. The } \\
\text { team } 2 \text { was constituted } \\
\text { by co-opting } 10-11 \text { HCP } \\
\text { working in the pediatric } \\
\text { emergency. It consisted } \\
\text { of an administrator, } \\
\text { educator, leader, and } \\
\text { executive and monitor- } \\
\text { ing team. The function } \\
\text { of each member of team } \\
2 \text { was explained to them } \\
\text { and was also displayed } \\
\text { in the unit for further } \\
\text { clarification of roles. } \\
\text { During this PDSA, the } \\
\text { complete control was } \\
\text { maintained by this team } \\
\text { of ER unit. }\end{array}$ & $\begin{array}{l}\text { During this PDSA, } \\
\text { infection control } \\
\text { nurse was introduced. } \\
\text { Her main role was to } \\
\text { conduct a sensitization } \\
\text { program each month } \\
\text { along with team } \\
\text { leaders for all new res- } \\
\text { idents and nurses. She } \\
\text { observed the practice } \\
\text { bundle for compliance } \\
\text { and sent reminders to } \\
\text { HCPs to make them } \\
\text { adhere to the bundle. } \\
\text { This process ensured } \\
\text { that all people working } \\
\text { in the unit were sensi- } \\
\text { tized to the interven- } \\
\text { tions. }\end{array}$ & $\begin{array}{l}\text { The motivation and } \\
\text { positive reinforcement } \\
\text { of the HCP toward ad- } \\
\text { herence to the bundle } \\
\text { were done by the leader } \\
\text { and other team mem- } \\
\text { bers in the fourth PDSA } \\
\text { cycle. The incentives } \\
\text { for good practices were } \\
\text { recognized and appre- } \\
\text { ciated by displaying the } \\
\text { names of HCP who were } \\
\text { exemplary in their work } \\
\text { on unit's notice board, } \\
\text { giving appreciation } \\
\text { cards and acknowl- } \\
\text { edging good work in } \\
\text { combined audits. }\end{array}$ \\
\hline
\end{tabular}


Each PDSA cycle described in Table 1 was conducted for 1 or 2 weeks; within 5 to 6 weeks, the bundle's compliance increased in the weekly audits. The incorporation of positive change within the unit was a sign of sustainable improvement. HCP fully accepted the bundle. There was a minimum cost of trays, but no extra staff was involved in implementing the bundle.

\section{Results}

The clinical and demographic characteristics of the study subjects are presented in Tables 2 and 3.

From June to September 2017, 185 children and 46 HCP were enrolled in the study. The majority of the children were boys both in the preassessment phase and all PDSAs. Among the HCPs, twothirds (71.7\%) were nurses and one-fourth (28.3\%) were doctors. The majority (76\%) of the HCP's were between 20 years and 30 years, with the mean \pm SD age being $29.1 \pm 6.1$ years. Nearly half of the nurses (47\%) were graduates (B.Sc Nursing), and one-third (26.1\%) of the doctors were MD Pediatrics trainees.

\section{Infiltration and Phlebitis in Preassessment and over 4 PDSA}

The preassessment findings revealed that the scores on the checklist of IV line insertion and drug administration ranged between 8.69 to $43.47 \%$ and 20.58 to $41.17 \%$, respectively. Also, the infiltration and phlebitis incidences were found to be 82.96 and $96.09 \%$, respectively.

The analysis was done through control charts, line graphs, and bar graphs over a period of time to determine the reduction in the incidence of phlebitis and infiltration (the outcome measures). Incidence of infiltration (Table 4, Fig. 3A) and phlebitis (Table 4, Fig. 3B) at 24, 24-48, 48-72, and 72-96 hours is depicted in the form of table and line graphs. In preassessment, one-fourth (25.9\%) of the children developed infiltration within 24 hours than a few (5\%) in PDSA 3. None of the children developed infiltration within 24 hours in PDSA 2 and PDSA 4. Less than half (41.9\%) of the children within 24-48 hours and only 5\% developed infiltration in PDSA 3. Almost half (51.4\%) of the children developed phlebitis between
Table 3: Sociodemographic cum clinical profile of healthcare personnel of pediatric emergency $(N=46)$

\begin{tabular}{lc}
\hline Observation & Frequency $n$ (\%) \\
\hline Designation & \\
Physicians & $13(28.3)$ \\
Nurses & $33(71.7)$ \\
Age (years) & \\
$20-30$ & $35(76)$ \\
$30-40$ & $7(15.2)$ \\
$40-50$ & $4(8.8)$ \\
Sex & \\
Male & $15(32.6)$ \\
Female & $31(67.4)$ \\
Professional qualification & \\
GNM & $5(10.9)$ \\
BSc Nursing & $22(47.8)$ \\
BSc (Post Basic) & $6(13.0)$ \\
MSc Nursing & $1(2.2)$ \\
MBBS and pursuing MD & $12(26.1)$ \\
Working experience in PGIMER & \\
0-5 years & $32(69.6)$ \\
5-10 years & $7(15.2)$ \\
$>10$ years & $7(15.2)$ \\
Working experience in pediatric emergency & \\
0-2 years & $17(37)$ \\
2-4 years & $14(30.4)$ \\
4-6 years & 5 years \\
\hline
\end{tabular}

24 hours and 48 hours, and only $10 \%$ of children developed phlebitis in PDSA 4 between 24 hours and 48 hours. There was an improvement in outcome measures, reduction in the incidence of infiltration and phlebitis; infiltration scores from 82.96 to $45 \%$ (Table 5) and phlebitis scores from 96.09 to $55 \%$ (Table 5).

There was an increase in overall scores for the process measures procedure of IV line insertion (20.54-88.99\%) (Fig. 4A) and administration of drugs through an IV line (50.16-68.40) (Fig. 4B).

Table 2: Clinical and demographic characteristics of study population $(N=185)$

\begin{tabular}{|c|c|c|c|c|c|}
\hline \multirow[b]{2}{*}{ Variables } & \multirow{2}{*}{$\begin{array}{l}\text { Preassessment group } \\
n=105(\%)\end{array}$} & \multicolumn{4}{|c|}{ PDSA cycles } \\
\hline & & $\begin{array}{l}\text { PDSA } 1 \\
n=20 \text { (\%) }\end{array}$ & $\begin{array}{l}\text { PDSA } 2 \\
n=20 \text { (\%) }\end{array}$ & $\begin{array}{l}\text { PDSA } 3 \\
n=20 \text { (\%) }\end{array}$ & $\begin{array}{l}\text { PDSA 4 } \\
n=20 \text { (\%) }\end{array}$ \\
\hline \multicolumn{6}{|l|}{ Age (years) } \\
\hline Median (Q1-Q3) & $4(1-7.5)$ & $7(3.5-9.5)$ & $4.5(2-7)$ & $4(1.62-6)$ & $3.5(1.12-5)$ \\
\hline \multicolumn{6}{|l|}{ Gender } \\
\hline Male & $66(62.9)$ & $10(50)$ & $15(75)$ & $13(65)$ & $19(95)$ \\
\hline Female & $39(37.1)$ & $10(50)$ & $5(25)$ & $7(35)$ & $1(5)$ \\
\hline \multicolumn{6}{|l|}{ Drugs } \\
\hline 1 Antibiotics & $14(13.3)$ & $3(15)$ & $8(40)$ & $2(10)$ & $8(40)$ \\
\hline 2 Antibiotics & $54(51.4)$ & $4(20)$ & $7(35)$ & $9(45)$ & $8(40)$ \\
\hline 1 Antiepileptic & $6(5.71)$ & $1(5)$ & - & $9(45)$ & - \\
\hline 2 Antiepileptic & 19 (18.09) & $4(20)$ & - & $1(5)$ & - \\
\hline Antiviral and antibiotics & $1(0.95)$ & $3(15)$ & $1(5)$ & $1(5)$ & - \\
\hline Antibiotics and antiepileptic & $5(4.76)$ & $1(5)$ & $2(5)$ & $1(5)$ & $1(5)$ \\
\hline Other & $6(5.71)$ & $4(20)$ & $1(5)$ & $2(10)$ & $2(10)$ \\
\hline Nil & - & - & $1(5)$ & $2(10)$ & $1(5)$ \\
\hline \multicolumn{6}{|l|}{ IV fluids } \\
\hline N/2 5\% dextrose & 72 (68.6) & $14(70)$ & $9(45)$ & $12(60)$ & $8(40)$ \\
\hline Other fluids ${ }^{* *}$ & $33(31.3)$ & $6(30)$ & $11(55)$ & $8(40)$ & $12(60)$ \\
\hline
\end{tabular}


QI to Reduce Infiltration and Phlebitis in Pediatric ER

Table 4: Percentage of infiltration and phlebitis within 24, 24-48, 48-72, 72-96 hours

\begin{tabular}{|c|c|c|c|c|c|}
\hline & $\begin{array}{l}\text { Preassessment } \\
n=105\end{array}$ & $\begin{array}{l}\text { PDSA } 1 \\
n=20\end{array}$ & $\begin{array}{l}\text { PDSA } 2 \\
n=20\end{array}$ & $\begin{array}{l}P D S A 3 \\
n=20\end{array}$ & $\begin{array}{l}\text { PDSA } 4 \\
n=20\end{array}$ \\
\hline \multicolumn{6}{|c|}{ Time of infiltration development } \\
\hline $0-24 \mathrm{hrs}$ & 25.9 & 15 & 0 & 5 & 0 \\
\hline 24-48 hrs & 41.86 & 20 & 20 & 5 & 0 \\
\hline $48-72$ hrs & 15.2 & 30 & 35 & 55 & 45 \\
\hline $72-96 \mathrm{hrs}$ & 1.9 & 0 & 15 & 15 & 20 \\
\hline Total & 84.86 & 65 & 60 & 80 & 65 \\
\hline \multicolumn{6}{|c|}{ Time of phlebitis development } \\
\hline $0-24 \mathrm{hrs}$ & 29.45 & 15 & 0 & 5 & 0 \\
\hline $24-48 \mathrm{hrs}$ & 51.41 & 20 & 30 & 10 & 10 \\
\hline $48-72$ hrs & 15.23 & 35 & 35 & 35 & 45 \\
\hline \multirow[t]{2}{*}{$72-96 \mathrm{hrs}$} & 2.85 & 5 & 15 & 15 & 30 \\
\hline & 98.98 & 75 & 80 & 65 & 85 \\
\hline
\end{tabular}
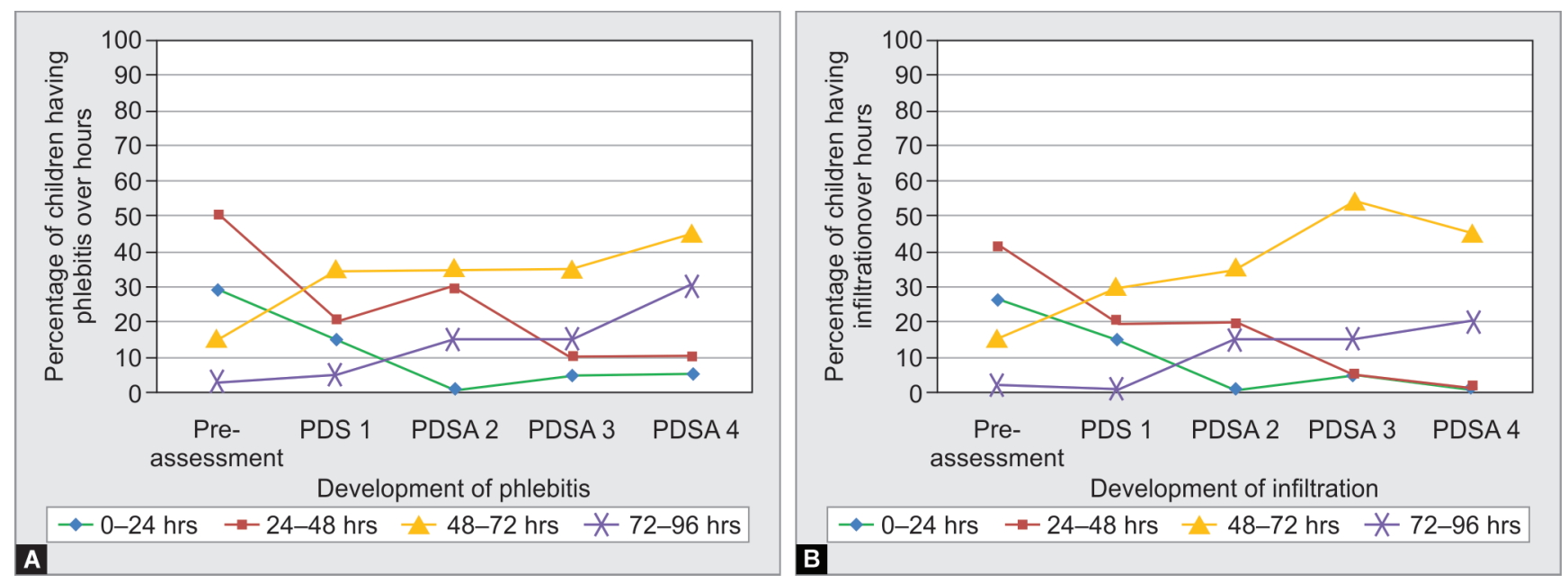

Figs 3A and B: (A) Line graph depicting incidence of infiltration within 24, 24-48, 48-72, 72-96 hours; (B) Line graph depicting incidence of infiltration in 24, 24-48, 48-72, 72-96 hours

Table 5: Incidence of the development of infiltration and phlebitis in preassessment and different PDSA cycles

\begin{tabular}{llllll}
\hline \multirow{2}{*}{ Phases } & \multicolumn{2}{l}{$\begin{array}{l}\text { Incidence of the development of } \\
\text { infiltration over a period of time }\end{array}$} & & $\begin{array}{l}\text { Incidence of the development } \\
\text { of phlebitis over a period of time }\end{array}$ \\
\cline { 2 - 3 } \cline { 5 - 6 } & $0-48$ hrs & $0-72$ hrs & & $0-48$ hrs & $0-72$ hrs \\
\hline Preassessment phase (105) & 67.5 & 82.96 & & 80.86 & 96.09 \\
PDSA 1 (20) & 35 & 65 & & 35 & 70 \\
PDSA 2 (20) & 20 & 55 & & 30 & 65 \\
PDSA 3 (20) & 10 & 65 & & 15 & 50 \\
PDSA 4 (20) & 0 & 45 & & 10 & 55 \\
\hline
\end{tabular}

The control chart of IV line insertion and maintenance shows a shift at the end of preassessment and in the PDSA cycles. There was a complete shift after PDSA 1 due to sensitization and interventions. There are two runs above the upper control limit, possibly due to the inclusion of lower preassessment scores. When improvement took place, the scores improved, and 2 data points shifted above the upper control limit. Over time, the process became stable in the subsequent PDSAs, which was evident in individual control charts provided in Figure 5. The balancing measure revealed that the opinion of HCPs changed from "not willing, finding difficult to the used tray and ANTT in an emergency, there is lack of supplies" to "good practice, became a normal routine, teamwork helped a lot, 


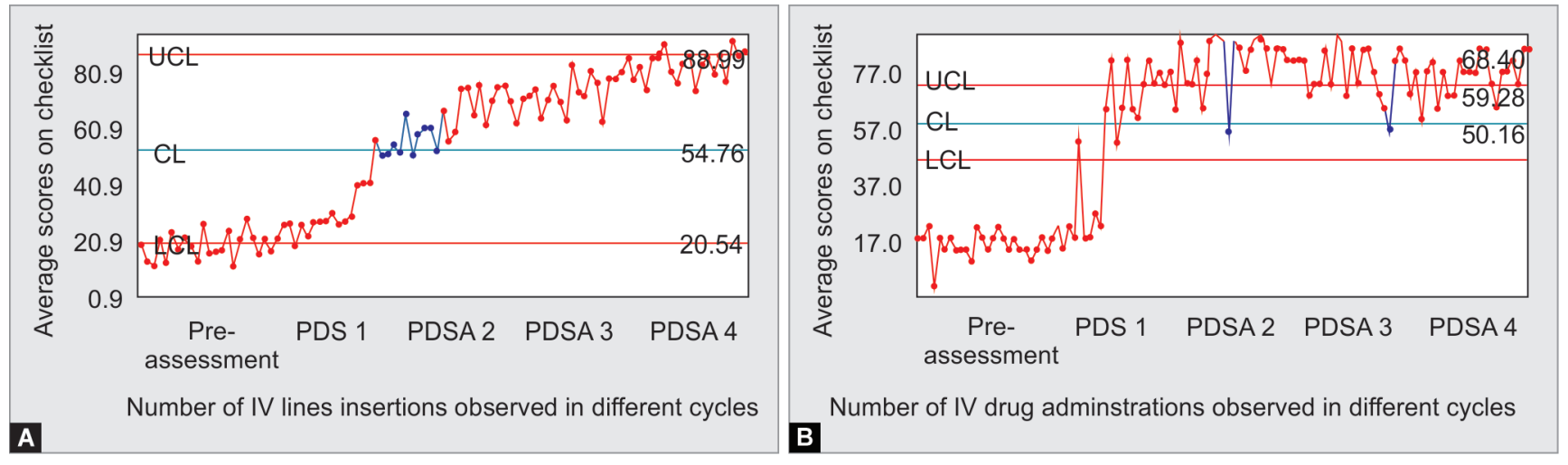

Figs 4A and B: (A) Consolidated charts for score on IV line insertion checklist; (B) Consolidated charts for score on IV drug administration checklist
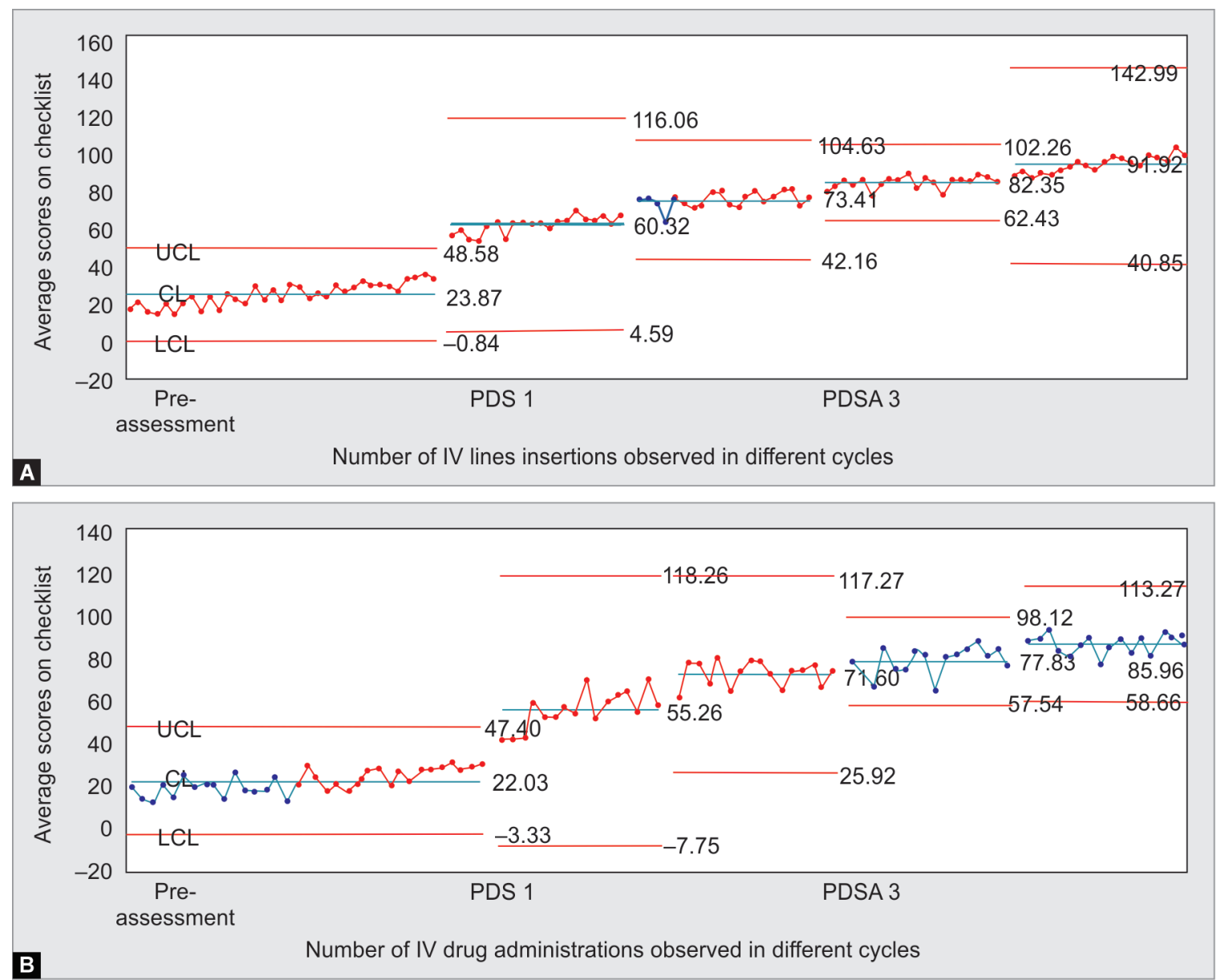

Figs 5A and B: (A) Average control charts of percent scores for IV line insertion checklist; (B) Average control charts of percent scores for score on IV drug administration checklist

this reduces chances of infection, try can be carried easily to bedside, the tray is low cost and easy to clean and use" over the 6 weeks.

\section{Discussion}

Peripheral IV line insertion in children is common in sick children in the pediatric ER. Nurses and physicians are responsible for the insertion and maintenance of the peripheral IV line and the prevention of complications related to its use. The prevention of infection remains the most significant ER challenge ${ }^{17}$ due to overcrowding, low nurse-patient ratio, and limited resources, especially in developing nations. ${ }^{33}$ Also, challenges are unique to every emergency setup that has to be effectively addressed. The challenges in our setup are that HCP is unable to follow all steps of proper aseptic practices and adhere stringently to them in an emergency setting ${ }^{34}$ where the pressure of getting things done fast within a specified time for acutely sick children is high. This task multiplies manifold when the unit is extremely crowded. In the preassessment phase, the strategy followed was mainly audit and feedback, considering its low to moderate efficacy in improving 
the practices. ${ }^{17,35,36}$ To prevent behavior modification by HCPs, a covert nonparticipatory assessment of existing practices related to aseptic techniques (using the checklist on IV line insertion and drug administration) and assessing the site for infiltration signs and phlebitis was done. We found a high incidence of infiltration and phlebitis in the preassessment phase, similar to that reported previously by White SA from Indiana. ${ }^{4}$

The incidence of phlebitis and infiltration scores reduced significantly after the introduction of the bundle. The present study introduced the low-cost trays, which provided a quick and easy mobile sterile surface, which was one example of a simple organizational change and effective utilization of resources. No such intervention has been tried in other studies to the best of our knowledge, especially in resource-limited settings. Before the intervention, we found that only $20 \%$ were following hand hygiene practices, and none were adhering to strict aseptic techniques for IV line insertion and maintenance. Postintervention, the score of hand hygiene improved to $80 \%$, and that of the aseptic technique was increased by 2-5 times. Hoot et al. also reported that after implementing the low resource interventions such as educational presentations, teachings in groups, posters with diagrams, and text messages on hand hygiene, improved practices significantly. ${ }^{33}$ The impact of continuous QI in clinical practice shows that evidencebased clinical application improves the outcome and reduces the cost of care. ${ }^{37}$ It has been shown that the implementation of evidence-based practices raises the standard for the prevention of infection and patient safety in an emergency department. ${ }^{17}$ Similarly, Hill reported that behavior and compliance of hand hygiene improved by QI projects. ${ }^{38}$

In the current study, the most critical barrier identified was the HCP's resistance to change. The reasons for this were many: apprehension about time and increased workload. They feared that implementing the bundle would be time-consuming and would overburden them as they were short-staffed. Apprehension about being observed and recorded was also a barrier to accepting the change. Their reluctance to use the compartment trays manifested in the form of hiding them and making several excuses for not using them. Initially, it was not easy to track the trays and other provided articles. HCP's verbal remarks were, "we do not want to use the trays; we will hide them." Acceptance gradually developed with continuous education, positive reinforcement, and motivation. Incentives to $\mathrm{HCPs}$ in the form of recognition and appreciation for good work, e.g., displaying HCP names with exemplary work on the unit's notice board, giving appreciation cards, and acknowledging good work in combined audits, were followed. Gradually HCPs accepted the change over time. Many authors have reported that incentives to $\mathrm{HCP}$ and positive reinforcement effectively enhance professional practices. $^{15-22,39,40}$

The finding of the study showed that adherence to the bundle was better with each PDSA cycle. We observed that over 6 weeks, while this QI project was on infiltration and phlebitis, incidence reduced to $38 \%$ and $41.09 \%$, respectively. Our findings are similar to another study conducted by Esteban et al., that identified challenges like hospital staff resistance to change, low nurse: patient ratio, and lack of resources and also reported that interventions provided over 3 weeks improved hand hygiene from 13.3 to $48.6 \% .^{27}$

The formation of Q1 teams further improves success, as was seen in our study. Weiner et al. also reported that hospital-level quality indicators with the QI team possessed higher values. ${ }^{41}$ The infection control nurse, introduced in PDSA 3 ensured adherence to the bundle by using checklists, taking feedback of practices, and suggesting remedial measures. Similarly, in another study by Ceballos et al., a nurse leader was initiated to ensure the use of infection control practices using the CLABSI checklist. She ensured the bundle's use and provided specific feedback on intervention compliance, which led to improvement. ${ }^{42}$ Motivation and improved adherence to bundle also improved with successive PDSA cycles and were best in PDSA 4. Alhassan et al. similarly reported that staff motivation and positive working conditions directly affect the standards in health facilities and patient safety. ${ }^{43}$

\section{SUMMARY}

There was an improvement in outcome measures. The reduction in infiltration and phlebitis incidence was from 82.96 to $45 \%$ and phlebitis scores from 96.09 to $55 \%$, respectively. The overall reduction of infiltration and phlebitis incidences was 38 and $41.09 \%$, respectively.

\section{Limitations}

The study period was brief, and the long-term impact of the change model has not been studied. Further PDSA to limit the other relevant variables impacting phlebitis and infiltration, such as the use of more fluid, more drugs of different $\mathrm{PH}$ were not included due to the limited time frame.

\section{Conclusion}

Although we planned a 50\% reduction for the primary outcome, we could only achieve 41.09 and $38 \%$ for phlebitis and infiltration, respectively. However, the extent of improvement seen reiterates that consistent regular efforts can improve it further. Regular feedback from team members and the motivation of the HCPs are helpful strategies. Also, the challenges of lack of resources can be overcome by low-cost local innovations. The aseptic IV line insertion and maintenance bundle need to be incorporated in the leading educational program and daily routine to achieve sustained benefits. It is replicable, and with practice, it will become a positive system change.

\section{ACKNOWLedgments}

The authors are deeply thankful to the nursing officers and senior residents for participating in this QI and making it a success. We would also like to thank Dr. Ashok Deorari, Professor and Head Department of Pediatrics, and team AlIMS, New Delhi, to continually teach QI science to the nurses/nursing students and residents. His leadership and vision have led to the development of substantial teaching-learning resources, including the point of care quality improvement module and many QI champions, including nurses.

\section{OrCID}

Neelima Singh (1) https://orcid.org/0000-0002-3660-6659 Geetanjli Kalyan (1) https://orcid.org/0000-0001-8749-563X Sukhwinder Kaur $\odot$ https://orcid.org/0000-0002-6969-7788 Muralidharan Jayashree 이 https://orcid.org/0000-0002-6149-1355 Sandhya Ghai @ https://orcid.org/0000-0003-0470-8025

\section{References}

1. Tagalakis V, Kahn SR, Libman M, Blostein M. The epidemiology of peripheral vein infusion thrombophlebitis: a critical review. Am J Med 2002;113(2):146-151. DOI: 10.1016/s0002-9343(02)01163-4. 
2. Cho YH, Yen LL, Yu KL, Chang CC, Chen HL. Reducing the incidence of phlebitis related to intravenous injection in pediatric patients. $\mathrm{Hu}$ Li Za Zhi 2015;62(3 Suppl.):49-57. DOI: 10.6224/JN.62.3S.49.

3. Phlebitis: a painful complication of peripheral IV. Am J Nurs. LWW. [cited 2018 Oct 16]. Available from: https://dev-journals2013. Iww.com/ajnonline/Fulltext/2003/02000/Phlebitis_A_painful_ complication_of_peripheral_IV.27.aspx.

4. White SA. Peripheral intravenous therapy-related phlebitis rates in an adult population. J Intraven Nurs Off Publ Intraven Nurs Soc 2001;24(1):19-24.

5. Kaur $\mathrm{P}$, Thakur R, Kaur S, Bhalla A. Assessment of risk factors of phlebitis amongst intravenous cannulated patients. Iran J Nurs Midwifery Res 2011;7(3):9.

6. Reingardiene D. Intravenous catheters and nosocomial infection. Med Kaunas Lith 2004;40(1):84-91.

7. Rosenthal VD, Guzman S, Migone O, Crnich CJ. The attributable cost, length of hospital stay, and mortality of central line-associated bloodstream infection in intensive care departments in Argentina: a prospective, matched analysis. Am J Infect Control 2003;31(8):475480. DOI: $10.1016 /$ j.ajic.2003.03.002.

8. Ling ML, Apisarnthanarak A, Madriaga G. The burden of healthcareassociated infections in Southeast Asia: a systematic literature review and meta-analysis. Clin Infect Dis 2015;60(11):1690-1699. DOI: 10.1093/ cid/civ095.

9. Cunha BA. Intravenous line infections. Crit Care Clin 1998;14(2):339346. DOI: 10.1016/s0749-0704(05)70399-7.

10. Sodhi J, Satpathy S, Sharma DK, Lodha R, Kapil A, Wadhwa N, et al. Healthcare associated infections in paediatric intensive care unit of a tertiary care hospital in India: hospital stay \& extra costs. Indian J Med Res 2016;143(4):502-506. DOI: 10.4103/0971-5916.184306.

11. Maki DG, Ringer M. Risk factors for infusion-related phlebitis with small peripheral venous catheters. A randomized controlled trial. Ann Intern Med 1991;114(10):845-854. DOI: 10.7326/0003-4819-11410-845.

12. Park SM, Jeong IS, Jun SS. Identification of risk factors for intravenous infiltration among hospitalized children: a retrospective study. PLoS One 2016;11(6):e0158045. DOI: 10.1371/journal.pone.0158045.

13. Catney MR, Hillis S, Wakefield B, Simpson L, Domino L, Keller S, et al. Relationship between peripheral intravenous catheter Dwell time and the development of phlebitis and infiltration. J Infus Nurs Off Publ Infus Nurses Soc 2001;24(5):332-341. DOI: 10.1097/00129804200109000-00008.

14. Singh N, Kalyan G, Kaur S, Murlidharan J, Ghai S. A study to find out the barriers and facilitators related to IV line insertion and maintenance in pediatric emergency. J Pediatr Crit Care 2018;5(1):63-63. DOI: 10.21304/2018.0501.00252.

15. Perl TM, Blot K, Bergs J, Vogelaers D, Blot S, Vandijck D. Prevention of central line-associated bloodstream infections through quality improvement interventions: a systematic review and meta-analysis. Clin Infect Dis Off Publ Infect Dis Soc Am 2014;59(1):96-105. DOI: 10.1093/cid/ciu239.

16. Boyd S, Aggarwal I, Davey P, Logan M, Nathwani D. Peripheral intravenous catheters: the road to quality improvement and safer patient care. J Hosp Infect 2011;77(1):37-41. DOI: 10.1016/j. jhin.2010.09.011.

17. Liang SY, Theodoro DL, Schuur JD, Marschall J. Infection prevention in the emergency department. Ann Emerg Med 2014;64(3):299-313. DOI: 10.1016/j.annemergmed.2014.02.024.

18. Mauger B, Marbella A, Pines E, Chopra R, Black ER, Aronson N. Implementing quality improvement strategies to reduce healthcareassociated infections: a systematic review. Am J Infect Control 2014;42(10 Suppl.):S274-S283. DOI: 10.1016/j.ajic.2014.05.031.

19. 10 Best strategies for infection prevention and control [Internet] [cited 2018 Oct 16]. Available from: https://www.beckershospitalreview. com/quality/10-best-strategies-for-infection-prevention-andcontrol.html.
20. Aseptic non touch technique $\left(\mathrm{ANTT}^{\oplus}\right)$ for intravenous therapy [Internet] [cited 2018 Oct 16]. Available from: https://www.gosh. nhs.uk/health-professionals/clinical-guidelines/aseptic-non-touchtechnique-antt-intravenous-therapy.

21. Implementing the aseptic non touch technique (ANTT ${ }^{\circledR}$ ) clinical practice framework for aseptic technique: a pragmatic evaluation using a mixed method... - PubMed - NCBI [Internet] [cited 2018 Oct 16]. Available from: https://www.ncbi.nlm.nih.gov/ pubmed/29317909.

22. Road Map to Eliminate HAI: 2013 Action Plan Conference. 2013;89.

23. Methods to improve healthcare worker hand hygiene to decrease infection in patient care [Internet] [cited 2018 Oct 16]. Available from:/CD005186/EPOC_methods-improve-healthcare-worker-handhygiene-decrease-infection-patient-care.

24. A culture of support: 4 ways to improve hand hygiene compliance [Internet] [cited 2018 Oct 16]. Available from: https://www. beckershospitalreview.com/quality/a-culture-of-support-4-waysto-improve-hand-hygiene-compliance.html.

25. Rowley S, Clare S. ANTT: a standard approach to aseptic technique. Nurs Times 2011;107(36):12-14.

26. Infusion Nurses Society. Infusion nursing standards of practice. J Infus Nurs Off Publ Infus Nurses Soc 2006;29(1 Suppl.):S1-S92. DOI: 10.1097/00129804-200601001-00001.

27. Esteban E, Ferrer R, Urrea M, Suarez D, Rozas L, Balaguer M, et al. The impact of a quality improvement intervention to reduce nosocomial infections in a PICU. Pediatr Crit Care Med J Soc Crit Care Med World Fed Pediatr Intensive Crit Care Soc 2013;14(5):525-32. DOI: 10.1097/ PCC.0b013e31828a87cc.

28. Institute for healthcare improvement: how to improve [Internet] [cited 2018 Oct 16]. Available from: http://www.ihi.org:80/resources/Pages/ Howtolmprove/default.aspx.

29. VIP score [Internet] [cited 2020 Feb 1]. Available from: http://www. vipscore.net/.

30. Higgingson R. IV cannula securement: protecting the patient from infection. Br J Nurs Mark Allen Publ 2015;24(8):S23-S24, S26, S28. DOI: 10.12968/bjon.2015.24.sup8.s23.

31. Webster J, Osborne S, Rickard CM, New K. Clinically-indicated replacement versus routine replacement of peripheral venous catheters. Cochrane Database Syst Rev 2015;(8):CD007798. DOI: 10.1002/14651858.CD007798.pub4.

32. Abolfotouh MA, Salam M, Bani-Mustafa A, White D, Balkhy HH. Prospective study of incidence and predictors of peripheral intravenous catheter-induced complications. Ther Clin Risk Manag 2014;10:993-1001. DOI: 10.2147/TCRM.S74685.

33. Hoot NR, Aronsky D. Systematic review of emergency department crowding: causes, effects, and solutions. Ann Emerg Med 2008;52(2):126-136. DOI: 10.1016/j.annemergmed.2008.03.014.

34. Lemaster $\mathrm{CH}$, Agrawal AT, Hou P, Schuur JD. Systematic review of emergency department central venous and arterial catheter infection. Int J Emerg Med 2010;3(4):409-423. DOI: 10.1007/s12245010-0225-5.

35. de Vos M, Graafmans W, Kooistra M, Meijboom B, Van Der Voort P, Westert G. Using quality indicators to improve hospital care: a review of the literature. Int J Qual Health Care J Int Soc Qual Health Care 2009;21(2):119-129. doi: 10.1093/intqhc/mzn059.

36. Gould DJ, Moralejo D, Drey N, Chudleigh JH, Taljaard M. Interventions to improve hand hygiene compliance in patient care. Cochrane Database Syst Rev 2017;9:CD005186. DOI: 10.1002/14651858. CD005186.pub4.

37. Snyder SR, Favoretto AM, Baetz RA, Derzon JH, Madison BM, Mass $D$, et al. Effectiveness of practices to reduce blood culture contamination: a laboratory medicine best practices systematic review and meta-analysis. Clin Biochem 2012;45(13-14):999-1011. DOI: 10.1016/j.clinbiochem.2012.06.007.

38. Hill S. A behavior-focused hand hygiene quality improvement project. Nursing Graduate Publications; 2016. 
39. Forster DH, Krause G, Gastmeier P, Ebner W, Rath A, Wischnewski N, et al. Can quality circles improve hospital-acquired infection control? J Hosp Infect 2000;45(4):302-310. DOI: 10.1053/jhin.2000.0762.

40. McDonald KM, Sundaram V, Bravata DM, Lewis R, Lin N, Kraft SA, et al. Closing the quality gap: a critical analysis of quality improvement strategies. In: Care coordination, vol. 7. [Internet]. Rockville (MD): Agency for Healthcare Research and Quality (US); 2007 [cited 2020 Feb 1]. (AHRQ Technical Reviews). Available from: http://www.ncbi. nlm.nih.gov/books/NBK44015/.

41. Weiner BJ, Alexander JA, Shortell SM, Baker LC, Becker M, Geppert JJ. Quality improvement implementation and hospital performance on quality indicators. Health Serv Res 2006;41(2):307-334. DOI: 10.1111/j.1475-6773.2005.00483.x.

42. Ceballos K, Waterman K, Hulett T, Makic MBF. Nurse-driven quality improvement interventions to reduce hospital-acquired infection in the NICU. Adv Neonatal Care Off J Natl Assoc Neonatal Nurses 2013;13(3):154-163;quiz 164-165. DOI: 10.1097/ ANC.0b013e318285fe70.

43. Alhassan RK, Spieker N, van Ostenberg $\mathrm{P}$, Ogink A, Nketiah-Amponsah $\mathrm{E}$, de Wit TFR. Association between health worker motivation and healthcare quality efforts in Ghana. Hum Resour Health 2013;11(1):37. DOI: 10.1186/1478-4491-11-37. 